NASA Technical Memorandum 88297

\title{
Dynamic Stability and Handling Qualities Tests on a Highly Augmented, Statically Unstable Airplane
}

Joseph Gera and John T. Bosworth

(MASA-TH-88297) DYMEIC STABILITI AMD

GABDLIHG COLLITIES TBSTS OH $\triangle$ BIGHLY

AUGABETE. STATICALLY OUSTABLE AIRPLABE

(uASL) 16 p Avail: vTIS BC $102 /$ gR 101

$187-26920$

CsCl $01 \mathrm{TC} 63 / 08 ; 0092572$

August 1987

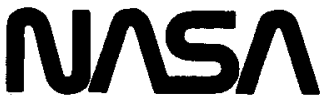

National Aeronautics and

Space Administration 
NASA Technical Memorandum 88297

\section{Dynamic Stability and Handling Qualities Tests on a Highly Augmented, Statically Unstable Airplane}

Joseph Gera and John T. Bosworth

Ames Research Center, Dryden Flight Research Facility, Edwards, California

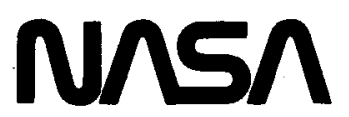

National Aeronautics and

Space Administration

Ames Research Center

Dryden Flight Research Facility

Edwards, California 93523-5000 


\author{
Joseph Gera ${ }^{*}$ and John T. Bosworth ${ }^{*}$ \\ NASA Ames Research Center \\ Dryden Flight Research Facility \\ Edwards, California
}

\begin{abstract}
Initial envelope clearance and subsequent flight testing of a new, fully augmented airplane with an extremely high degree of static instability can place unusual demands on the flight test approach. Previous flight test experience with these kinds of airplanes is very limited or nonexistent. The safe and efficient flight testing may be further complicated by a multiplicity of control effectors that may be present on this class of airplanes. This paper describes some novel flight test and analysis techniques in the flight dynamics and handling qualities area. These techniques were utilized during the initial flight envelope clearance of the X-29A airplane and were largely responsible for the completion of the flight controls clearance program without any incidents or significant delays.
\end{abstract}

\section{Nomenclature}

A, B, C, D

ARI

FFT

RAI

$\mathbf{x}$

$\dot{\mathbf{x}}$

$\mathbf{X}_{\mathbf{R}}$

$\mathbf{X}_{\mathbf{Y}}$ matrices defining the linearized mathematical model of the test airplane

aileron-to-rudder interconnect gain

fast Fourier transform

rudder-to-aileron interconnect gain

state vector

time derivative of state vector

input sequence for open-loop roll frequency response

input sequence for open-loop yaw frequency response

\footnotetext{
*Aerospace Engineer. Member AIAA.
}

The abstract of this paper was submitted by the authors to the Society of Flight Test Engineers and was accepted by the Society for presentation at its 18th Annual Symposium, Amsterdam, Sept. 28 - Oct. 2, 1987. y

$\mathbf{Y}_{\mathbf{R}}$

$\mathbf{Y}_{\mathbf{Y}}$

$\mathbf{u}$

output vector

output sequence for open-loop roll frequency response

output sequence for open-loop yaw frequency response

control vector

Introduction

The X-29A airplane, which began the initial flight tests in late 1984, is a fascinating example of a statically unstable, highly augmented, multisurface airplane. Its evolution, design, development, and initial flight test results are documented in Refs. 1 to 11. This paper describes those flight test techniques that were used for the first time at NASA Ames Research Center, Dryden Flight Research Facility (AmesDryden), in the flight dynamics and flying qualities area and contributed considerably to the safe and efficient flight testing of the airplane.

The most significant of these techniques, from the point of view of ensuring that adequate levels of dynamic stability existed at each test point, is the nearreal-time computation of the open-loop frequency response of the X-29A in the pitch axis from pilot-generated frequency sweeps. The frequency sweeps had to be performed with all the feedback loops left intact because of the extreme static instability of the unaugmented airframe. The open-loop frequency response yielded the actual gain and phase margins immediately, allowing a quick comparison with precomputed stability margins stored for each test point. Any unexpected nonlinearities, such as position or rate saturation of actuators or time delays associated with data conversion between the analog and digital elements of the airplane, were reflected in reduced stability margins. Gain scheduling errors due to unmodeled air data characteristics also became obvious long before any indications were given by conventional flight test techniques. The utilization of the open-loop frequency response tumed out to be a highly successful endeavor in other respects as well: It resulted in a roughly 30 percent reduction in the time allotted for initial envelope clearance. 
Although not related directly to safety-of-flight issues, the closed-loop frequency responses of the pitch and roll axes were also computed by the same transform algorithms. This computation, followed by finding the lower order equivalent system dynamics, allowed a rigorous application of current military handling qualities specifications to the X-29A aircraft during the early phases of the flight test program.

Recent improvements in the computational capabilities at Ames-Dryden allow many routine data processing tasks to be performed in real time because of the utilization of extremely fast parallel processing of the data. One of the first utilizations of this capability is the comparison of X-29A flight data with the output of the linearized simulation in real time.

\section{Test Objectives}

The main objective in the flight controls discipline was the demonstration of the design dynamic stability levels during $1-\mathrm{g}$ flight in each of the control system modes that could be selected easily by the pilot. In addition to the normal digital mode, the pilotselectable modes include a digital and an analog reversion mode. The verification of the design margins during 1-g trimmed flight was felt to be sufficient to extrapolate to higher load factors by using either analytical or simulator results.

Since the determination of stability levels reveals little about how the airplane flies as far as the pilot is concerned, a parallel test objective was to establish the handling qualities of the X-29A airplane with the assumption that the requirements for highmaneuverability airplanes apply.

\section{Flight Test Approach}

Flight testing of the X-29A airplane was different from routine evaluation of the airplane in flight since many new technologies were incorporated into the design. From the flight controls point of view the most significant of these new technologies were the approximately 35-percent static instability of the airframe, the digital fly-by-wire primary flight control system, and three kinds of pitch control surfaces: canards, symmetric flaps, and strake flaps. The general arrangement of these surfaces is shown in Fig. 1. The approach to the initial flight tests and envelope clearance was influenced to a significant extent by the new technologies incorporated in the flight control system.

Originally, the design criterion for dynamic stability was the usual requirement of $6 \mathrm{~dB}$ and $45^{\circ}$ of gain and phase margins, respectively. As the final control system design evolved, however, it was found that these requirements were not met in the longitudinal axis when the analysis included higher order dynamics. Since the requirements are usually applied to airplanes in series production, they were relaxed for the $\mathrm{X}-29 \mathrm{~A}$ airplane, an experimental aircraft built for flight research. The relaxed requirements are shown on a typical open-loop frequency response plot for the pitch axis in Fig. 2. This plot is obtained from the linear transfer function model of the augmented airplane.

After encouraging results from simulation and postflight analysis of the data from the initial flights, the procedure for measuring frequency responses, shown in Fig. 3, evolved and was used with considerable success throughout the envelope clearance program. The procedure involves the computation of the open-loop frequency response while all feedback loops remain intact. The computation relies on a fast Fourier transform (FFT) algorithm, which is executed in a high-speed parallel processor on the ground using telemetered data from the test aircraft as input. As shown in Fig. 3, the input and output sequences to the FFT, designated as $\mathrm{X}$ and $\mathrm{Y}$, respectively, are the error and feedback signals in the pitch axis control loop. Excitation of the loop is provided either by the pilot through the command shaping path or by an uplinked signal that is summed with the pilot command. Although the latter approach results in more precise control of the excitation signal, it was found in practice that the pilot-generated frequency sweeps were entirely satisfactory. The use of the uplinked signal became necessary for computing the frequency response of the roll and yaw axes whenever roll-to-yaw or yawto-roll interconnects are employed in the control system. Figure 4 is a schematic of such a system, which is similar to the $\mathrm{X}-29 \mathrm{~A}$ lateral-directional stability augmentation system. It can be seen from the figure that the total error and feedback signal cannot be used in either axis to define the open-loop frequency response through a Fourier transform since the pilotgenerated frequency sweep excites the control system through more than a single location. Although several possibilities exist for obtaining the open-loop roll and yaw axis frequency responses, the approach used for the $\mathrm{X}-29 \mathrm{~A}$ testing involved an uplinked frequency sweep signal directly summed into the aileron and rudder actuator commands. This procedure amounted to mathematically breaking either the roll or yaw axis feedback loop at the actuator while keeping the other loop closed. It is important to keep in mind, however, that no feedback loop was opened physically, thus flight safety was not compromised by the frequency response tests. 
In addition to monitoring dynamic stability in the frequency domain in near real time, the availability of the linearized mathematical model of the test airplane at each test condition and the high-speed data processing capability on the ground made it possible to compare the response of the airplane with that of the linearized simulation to identical pilot inputs in real time. This procedure is shown conceptually in Fig. 5. In practice the procedure involved the computation of the linear equatons of motion at each test condition immediately before flight from an all-FORTRAN, nonlinear simulation of the airplane. To facilitate the real-time solution of the linear differential equations, the state transition matrix was also computed for the sampling interval of the flight control computers, so that during flight only the solution of the difference equations was required. The comparison is made between the linear and measured time histories of the principal motion variables, such as pitch rate, angle of attack, and normal acceleration. The initial or trim values are subtracted from subsequent flight measurements in order to make the flight data directly comparable to the linear solutions.

The open-loop frequency domain analysis was also extended to include the computation of the closedloop frequency response of the airplane between longitudinal stick and pitch rate, and between lateral stick and roll rate. In contrast with the open-loop frequency response and the time history comparison, the closed-loop frequency responses were computed postflight. The objective of this work was to obtain a quantitative measure of handling qualities. The closedloop frequency responses were approximated in the frequency range of 0.3 to $10 \mathrm{rad} / \mathrm{sec}$ by a lower order system that also contained a pure time delay or transport lag term. The approximation yielded the equivalent modal response characteristics and the associated time delays. The lower order system characteristics could then be compared with the requirements for highmaneuverability airplanes. Data from this comparison and the pilot ratings and associated comments during standard handling qualities tasks revealed whether the requirements were applicable to airplanes with the unusual characteristics of the X-29A.

\section{Results and Discussion}

The envelope clearance of the X-29A airplane was accomplished in all selectable flight control system modes without any unusual occurrences such as control surface oscillations, limit cycles, or unforeseen interactions between the flight control system and the structure. The airplane appeared to the pilot to be well damped in all axes, and the control surfaces were quiet in flight. Transitions among the flight control system modes and between the ground and air were smooth.

\section{Qpen-Loop Frequency Response}

The computation of the open-loop frequency responses turmed out to be a surprisingly trouble-free operation. For the longitudinal axis, the computation was performed as soon as enough data were accumulated for the FFT algorithm. For the particular FFT algorithm in question, this was the case after accumulating 2048 data points. This required $52 \mathrm{sec}$ of trimmed flight during which the pilot performed not only a pitch stick frequency sweep but also a series of longitudinal pulses and doublets. The execution of the FFT algorithm required a negligible amount of computer time, and a video display of the frequency response and the associated stability margins was produced in less than $3 \mathrm{sec}$. Figure 6 shows a typical pitch axis open-loop frequency response plot obtained during flight. Also shown is the frequency response predicted by linear analysis at the same flight condition. A remarkably close fit between the flight data and the prediction may be noted in the rigid-body frequency range. Generally, this was the case below and above transonic Mach numbers, indicating where the mathematical modeling of the airplane was most successful. It should be noted that the flight data were consistent and repeatable everywhere in the flight envelope. In fact, the frequency response determined from flight data was of sufficiently high quality that it was possible to make changes in the pitch axis control system loop gain based solely on the frequency response results. An example of this is shown in Fig. 7. The initial determination of the open-loop frequency response clearly shows that the value of the loop gain is too high by approximately $2.5 \mathrm{~dB}$, resulting in inadequate stability margins. Reducing the loop gain by this amount by simply changing the flight control system software restored the stability margins to nearly optimal values. This gain change was the only major control law change that affected stability, and it was accomplished during scheduled airplane maintenance without any delay in the envelope clearance program. With this change in place, the longitudinal dynamic stability exceeds the minimum margin requirements throughout the flight envelope. This example demonstrates the utility of the on-line frequency domain analysis of flight data; namely, the direct information on the overall system stability and the ability to make control system adjustments without the precise knowledge of conventional stability and control derivatives. In previous flight test programs, similar adjustments required a considerable amount of time for postflight data reduction, analysis, and gain correction. 
Since it is the pitch axis in which the X-29A airplane exhibits highly relaxed static stability characteristics, efforts to obtain stability margins during flight tests concentrated on the pitch axis. Attempts are being made to perform similar computations for the roll and yaw axes. Although no flight results have been obtained to date, simulator results are encouraging. Figures 8 and 9 show the comparison of linear predictions with nonlinear simulator results. As can be seen from these figures, the augmented X-29A airplane exhibits very generous stability margins in the lateral-directional axes; these margins are reasonably close to the predicted values obtained from linear analysis.

\section{Time History Comparison Using Flight and Linear Simulation Data}

To enhance flight safety during the initial envelope clearance, monitoring the stability margins was augmented by comparing time histories obtained during stick and rudder pulses and doublets in flight with time histories generated by the linearized simulation of the test airplane in response to identical pilot inputs. These inputs were obtained from the telemetry data and were used in real time to generate time histories that were paired with the corresponding flight data and displayed in the identical coordinate systems. A typical comparison plot is shown in Fig. 10 for pitch axis variables. For the pitch axis, due to the extreme instability of the unaugmented airframe, the linear mathematical model included not only the rigid airframe equations of motion but also the entire flight control system including such details as sensor dynamics, transport lag, notch filters, and antialiasing filters. For the longitudinal normal mode, this resulted in a 48 thorder linear system. The processing of this sytem in real time was well within the capability of the array processor that was utilized for the ground computation. The use of linear simulation for comparison with flight data is not without certain advantages over a complete nonlinear simulation. These advantages include the increased speed of computation necessary for real-time comparison and the ease of detecting unexpected nonlinearities by the test personnel.

For the lateral-directional axes, the comparison required considerably less computation. Since the test airplane does not have highly unstable modes in its lateral-directional characteristics, there was no need to model the entire flight control system. It was sufficient to consider the rigid airplane lateral-directional equations of motion, excited directly by the aerodynamic surface positions, which were available from telemetry data. A typical comparison plot is shown in Fig. 11. Although in the fine details of the motion the comparison is not as close as might be expected, it yields adequate information to ascertain in real time that the amplitudes, frequencies, and damping levels are close enough to predictions that flight safety is not compromised.

\section{Closed-Loop Erequency Response}

Closed-loop frequency response characteristics were obtained for both the longitudinal and the lateraldirectional axes. For the longitudinal axis, the frequency response was computed between the pitch stick displacement and pitch rate; for the lateral-directional axes, frequency response was computed between the roll stick displacement and roll rate. The pitch and roll frequency responses were then fitted in the mean square sense with a pure time delay term in conjunction with second- and first-order transfer functions, respectively. Figures 12 and 13 are examples of closed-loop frequency responses along with the results of the fitting procedure. Similar data were obtained throughout the flight envelope of the test airplane. According to the data, the airplane appeared to the pilot as a welldamped system in all axes.

In the pitch axis at some flight conditions the equivalent short-period damping ratios were above the maximum recommended values for high-maneuverability airplanes. At the highest dynamic pressures at which the airplane has been tested to date, the equivalent short-period frequencies were below the recommended values. The equivalent time delay in the pitch axis at all flight conditions was found to be slightly above the recommended values, being mostly in the 110- to 140 -msec range.

For the roll axis, the equivalent system results indicate that the roll mode time constant is in the neighborhood of $0.3 \mathrm{sec}$ throughout the flight envelope, well within the range of recommended values. As in the pitch axis, the equivalent time delay is slightly longer than the recommended $100 \mathrm{msec}$ or less, being in the 120- to 150-msec range.

A limited amount of testing was devoted to evaluating the handling qualities of the baseline flight control system during air-to-air tracking. In this context the term baseline means that no modifications or tuning of the control system had been made for the specific purpose of improving the handling qualities of the test airplane. The tasks used for the evaluation are shown in Fig. 14. In each task except the simulated terrain following, the lead T-38 airplane was performing turn reversals either at the request of the X-29A pilot or randomly while gradually increasing the load factor up to $3 \mathrm{~g}$. The simulated terrain following was a pure pitch axis task in which the lead airplane performed mild pushover-pullup sequences at load factors varying between 0.5 and $2.5 \mathrm{~g}$. Since this task proved to be the most difficult for the X-29A airplane, the task was also performed by each pilot in another T-38 
airplane. Figure 15 summarizes the pilot ratings. The results show that the airplane has satisfactory characteristics for the tasks, with some minor deficiencies that warrant some flight control system improvements. Before discussing the deficiencies, it should be noted that the airplane handled remarkably well considering the number of new technologies incorporated in its design and the fact that no control law changes had been made for improving the handling characteristics. It is worth noting that one pilot found the air-to-air tracking characteristics to be excellent. preferred

Pilot comments indicated that they would have

- slightly faster initial pitch response,

- better stick geometry since pitch stick travel is too large in comparison with lateral stick travel, and

- lower lateral sensitivity for small stick inputs, faster roll rate for large stick inputs.

In general, it was found that the current handling qualities requirements are applicable to the X-29A airplane, although more testing will be required to show whether the equivalent time delays indicated by the analysis can be better reconciled with pilot comments.

\section{Concluding Remarks}

The initial envelope clearance of a statically unstable, highly augmented airplane required a significant amount of on-line data processing. Examples from the $X-29 A$ flight tests illustrate that the openloop frequency response of an airplane with highly relaxed static stability can be successfully computed on the ground from telemetry data. The data were obtained while all feedback loops remained intact, so the process did not compromise flight safety. The required computation and graphical display of the results, which included the gain and phase margins, were performed in less than $3 \mathrm{sec}$. In the pitch axis where the flight control system is essentially of a single-input, singleoutput type, the frequency sweep required to excite the system was performed manually by the pilot. In the lateral-directional axes where the stability augmentation is accomplished by a simple example of a multiinput, multioutput system, the required frequency sweep will be uplinked from the ground directly to the aileron and rudder actuation system.

The on-line procedure that utilizes a fast Fourier transform algorithm yielded open-loop frequency response data that were consistent and repeatable throughout the flight envelope of the X-29A test airplane. The data were used as the principal means of monitoring the level of pitch axis dynamic stability throughout the envelope clearance flights. In addition, the data allowed the verification of the linear mathematical model of the test airplane and were used for redesigning the pitch axis loop gain at transonic, low-altitude flight conditions.

The availability of a linear mathematical model of the test airplane allowed the real-time computation of predicted time histories using the pilot inputs from telemetry. These time histories were compared with flight data, also in real time. The comparison not only allowed an immediate assessment of frequencies and damping levels at new test points but also gave a clear indication of any nonlinear behavior of the airplane, which could result from rate or position saturation of any component of the flight control system.

Postflight closed-loop frequency response data were obtained from pilot-generated frequency sweeps. These were fitted numerically with a lower order equivalent system, which yielded the equivalent time delay and modal response characteristics. The results indicate that the current handling qualities requirements for high-maneuverability airplanes are generally applicable to the X-29A airplane.

\section{References}

1 Krone, N.J., Jr., "Forward Swept Wing Flight Demonstrator," AIAA-80-1882, Aug. 1980.

25pacht, G., "The Forward Swept Wing: a Unique Design Challenge," AIAA-80-1885, Aug. 1980.

3Whitaker, A., and Chin, J., "X-29 Digital Flight Control System Design," AGARD-CP-384, Active Control Systems - Review, Evaluation, and Projections, Oct. 1984.

${ }^{4}$ Ishmael, Stephen D., and Wierzbanowski, Ted, "X29 Initial Flight Test Results," SETP 29th Symposium Proceedings, 1985, pp. 95-113.

$5_{\text {Zislin, A., Laurie, E., Wilkinson, K., and Gold- }}$ stein, R., "X-29A Aeroservoelastic Analysis and Ground Test Validation Procedures," AIAA-85-3091, Oct. 1985.

${ }^{6}$ Sefic, Walter J., and Cutler, William, "X-29A Advanced Technology Demonstrator Program Overview," AIAA-86-9727, Apr. 1986.

${ }^{7}$ Smith, Rogers E., and Schroeder, Kurt C., "Flight Testing the X-29," SETP 30th Symposium Proceedings, 1986, pp. 116-134. 
${ }^{8}$ Gera, Joseph, "Dynamics and Controls Fiight Testing the X-29A Airplane," NASA TM-86803, 1986.

${ }^{9}$ Bosworth, J.T., and West, J.C., "Real-Time OpenLoop Frequency Response Analysis of Flight Test Data," AIAA-86-9738, Apr. 1986.

${ }^{10}$ Smith, R.E., and Sarrafian, S.K., "Effects of Time Delay on Flying Qualities: An Update," AIAA86-2202, Aug. 1986.

${ }^{11}$ Bauer, Jeffrey E., Crawford, David B., Gera, Joseph, and Andrisani, Dominick, "Real-Time Com- parison of X-29A Flight Data and Simulation Data," AlAA-87-0344, Jan. 1987.

12 Military Specification - Flight Control Systems Design, Installation and Test of Piloted Aircraft, General Specification for - MIL-F-9490D, June 1975. (Supersedes MIL-F-9490C, Mar. 1964.)

13 Military Specification - Flying Qualities of Piloted Airplanes. MIL-F-8785C, Nov. 1980. (Supersedes MIL-F-8785B, Aug. 1969.)
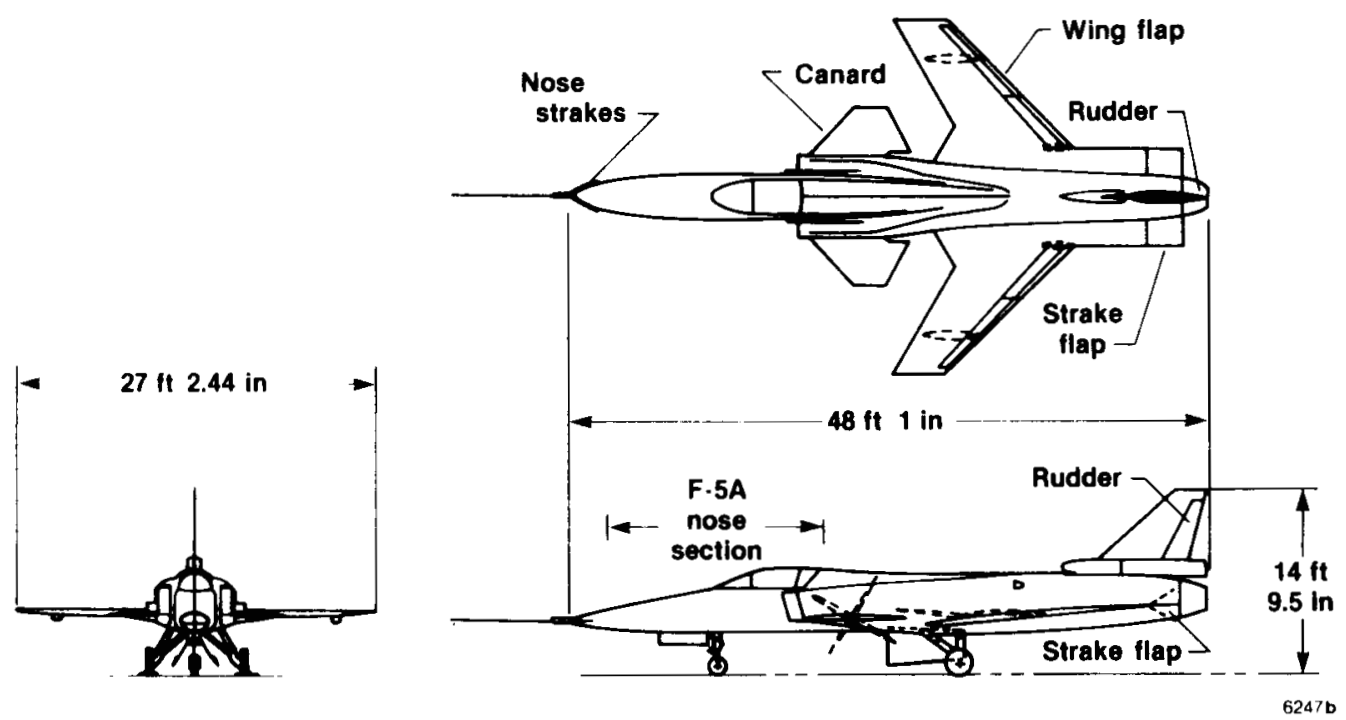

Fig. 1 X-29A airplane. 


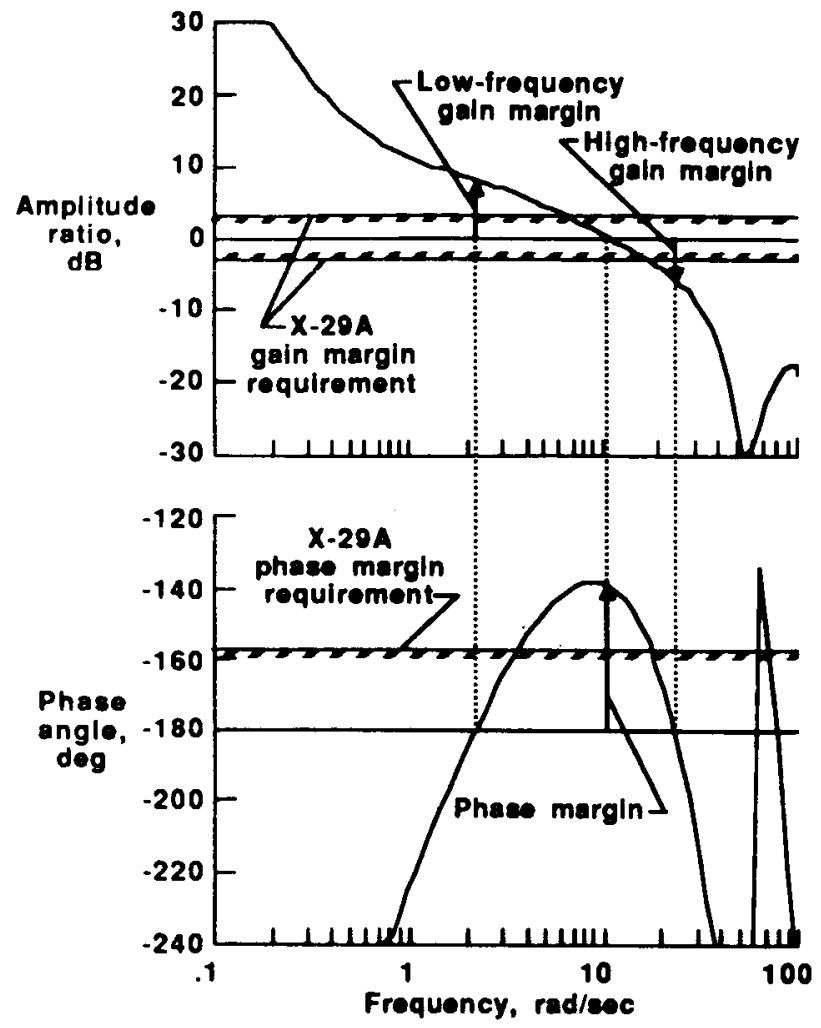

Fig. 2 Stability margin requirements for the $X$-29A envelope expansion program.

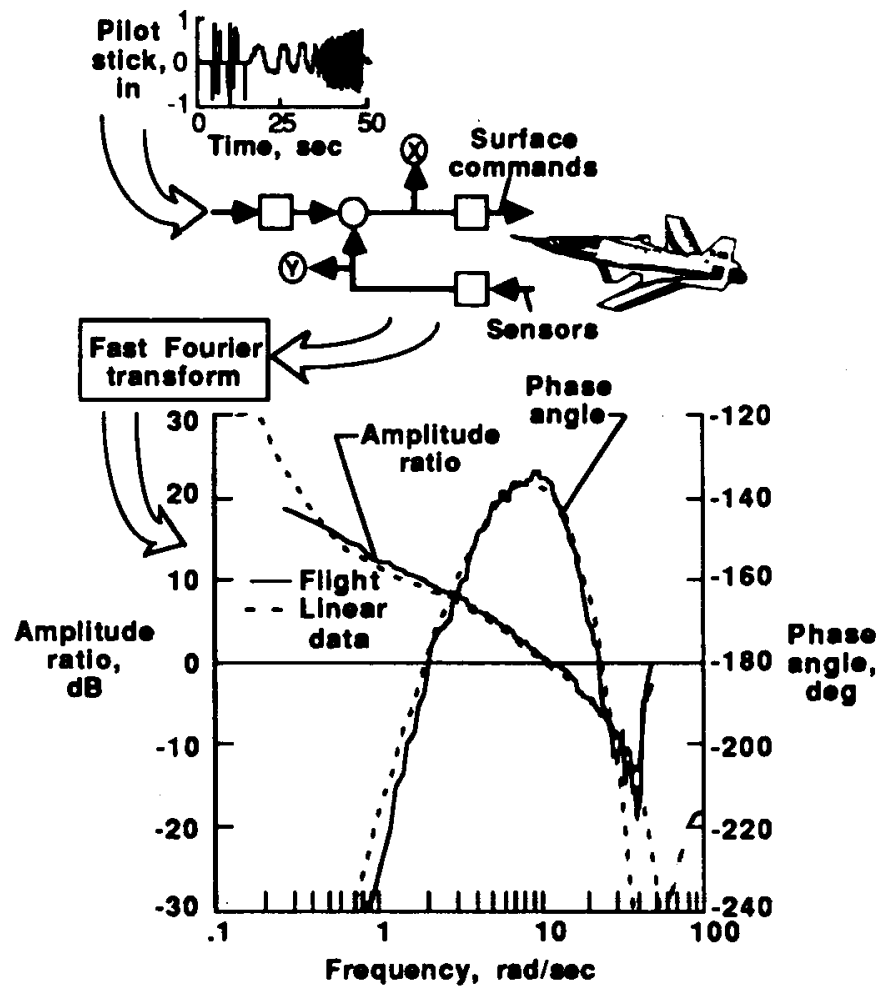

Fig. 3 Real-time frequency response analysis procedure.

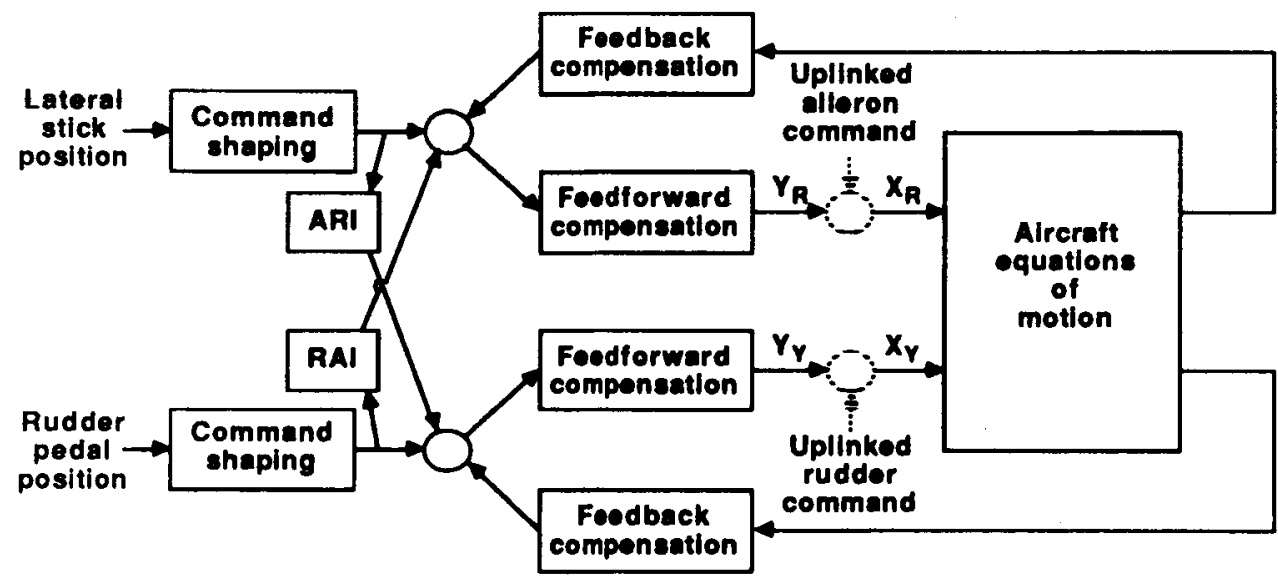

Fig. 4 Representative lateral-directional control system. 


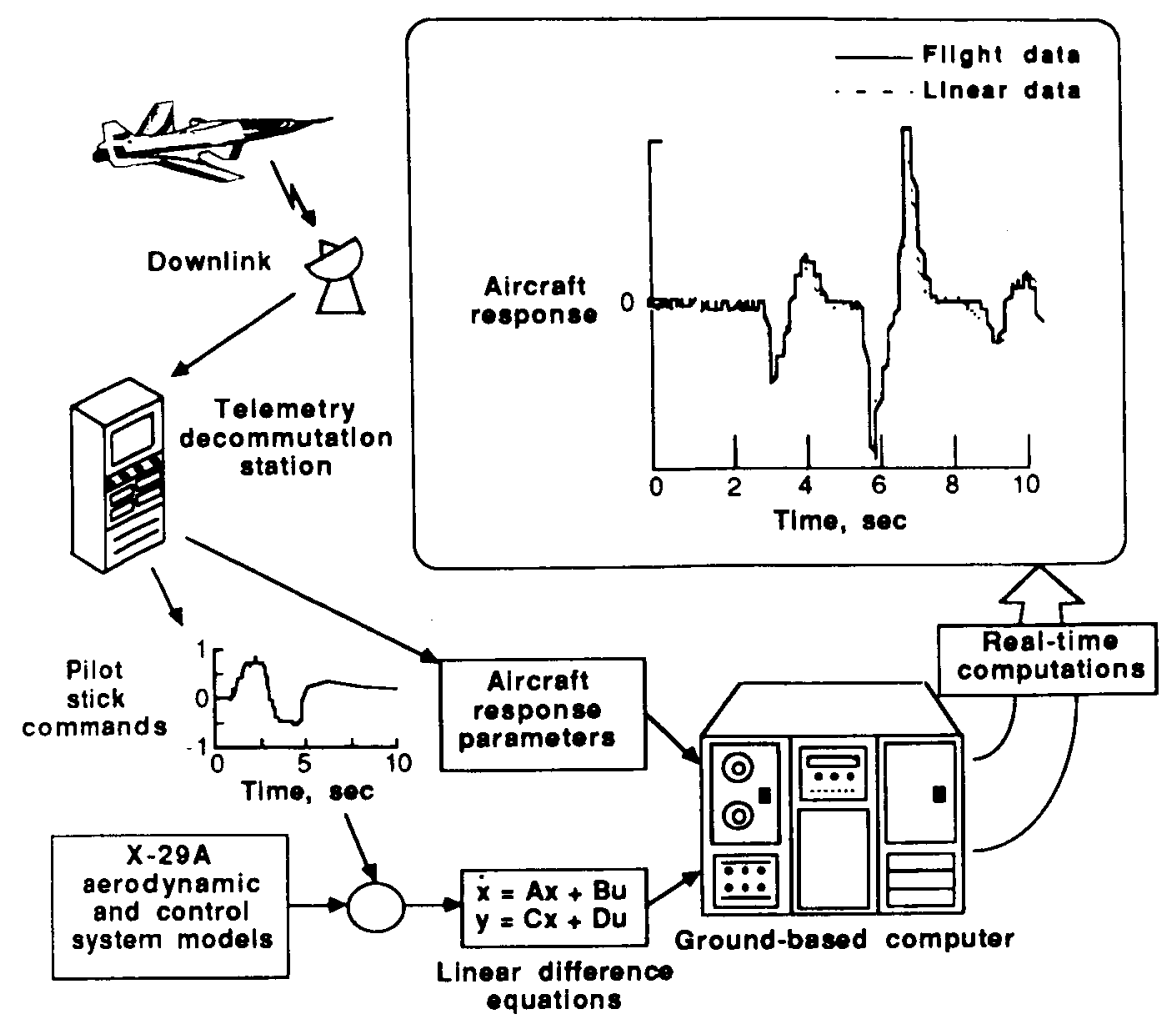

Fig. 5 Real-time comparison of linear simulation and flight.

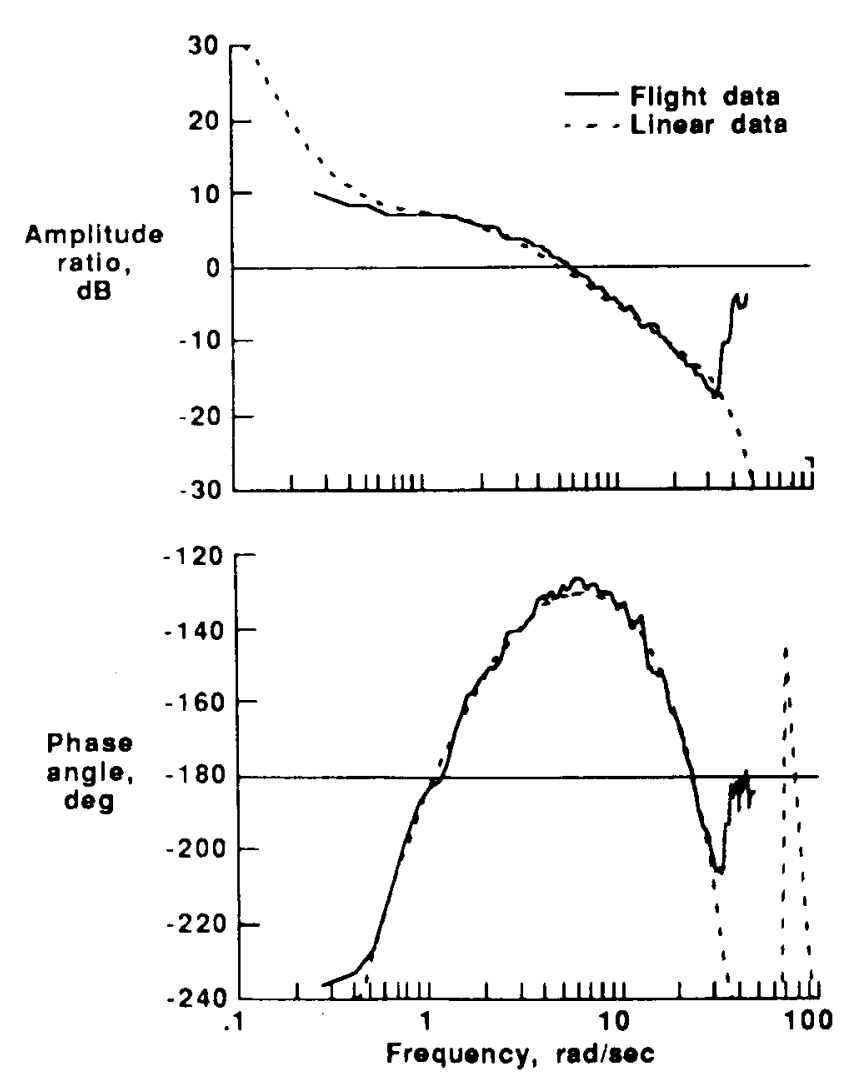

Fig. 6 Pitch axis open-loop frequency response flight data compared with linear analysis.

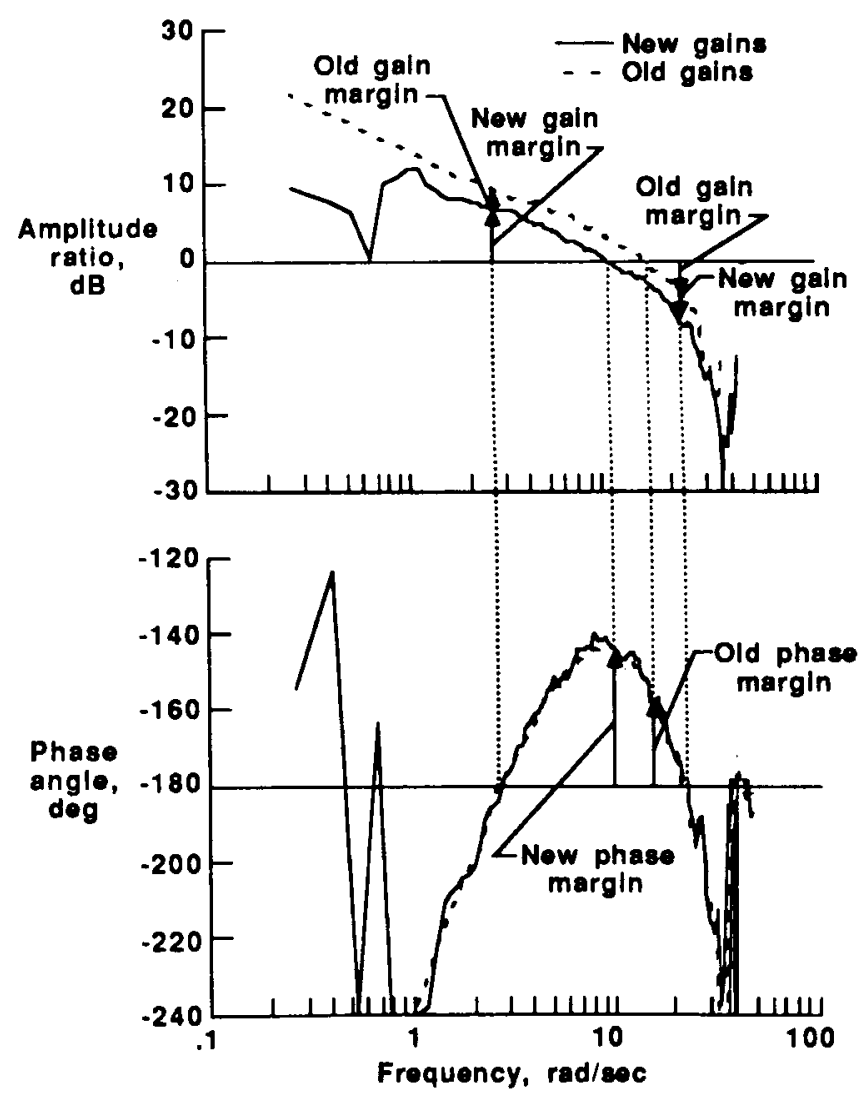

Fig. 7 Effect of gain change on flight-measured Bode plot. 

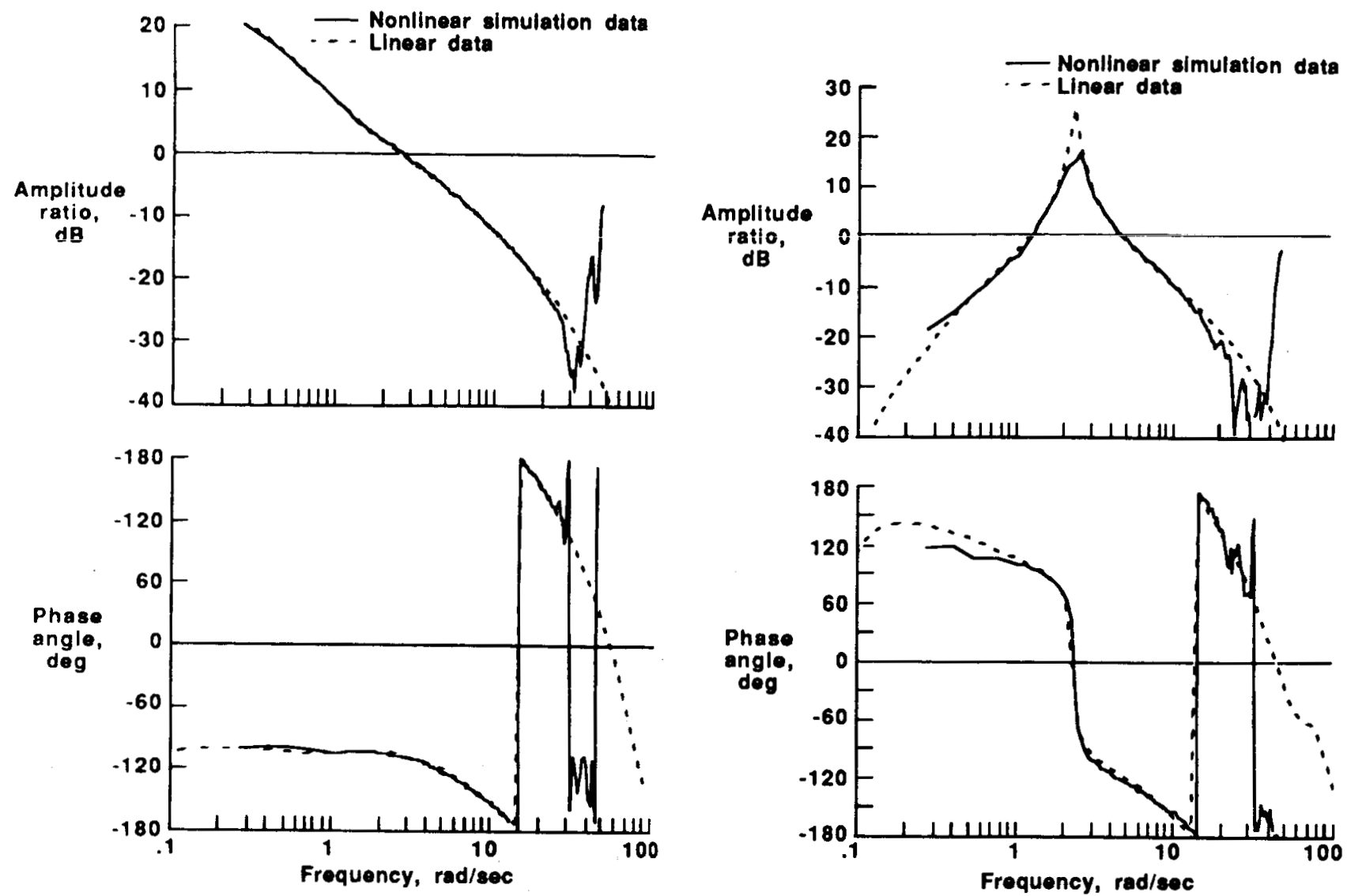

Fig. 8 Roll axis open-loop frequency response real-time simulation data compared with linear analysis.

Fig. 9 Yaw axis open-loop frequency response real-time simulation data compared with linear analysis. 

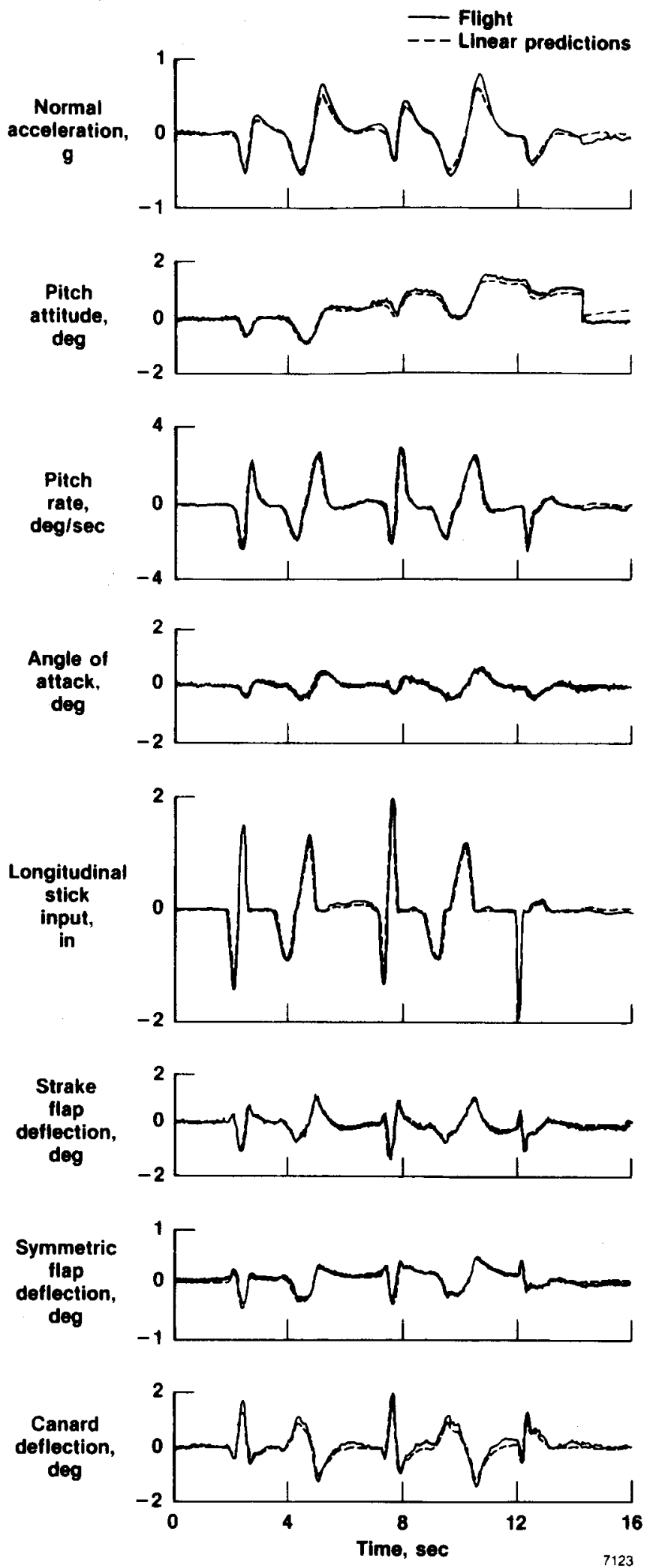

Fig. 10 Response of the X-29A to a pitch stick input compared with linear simulation results. 

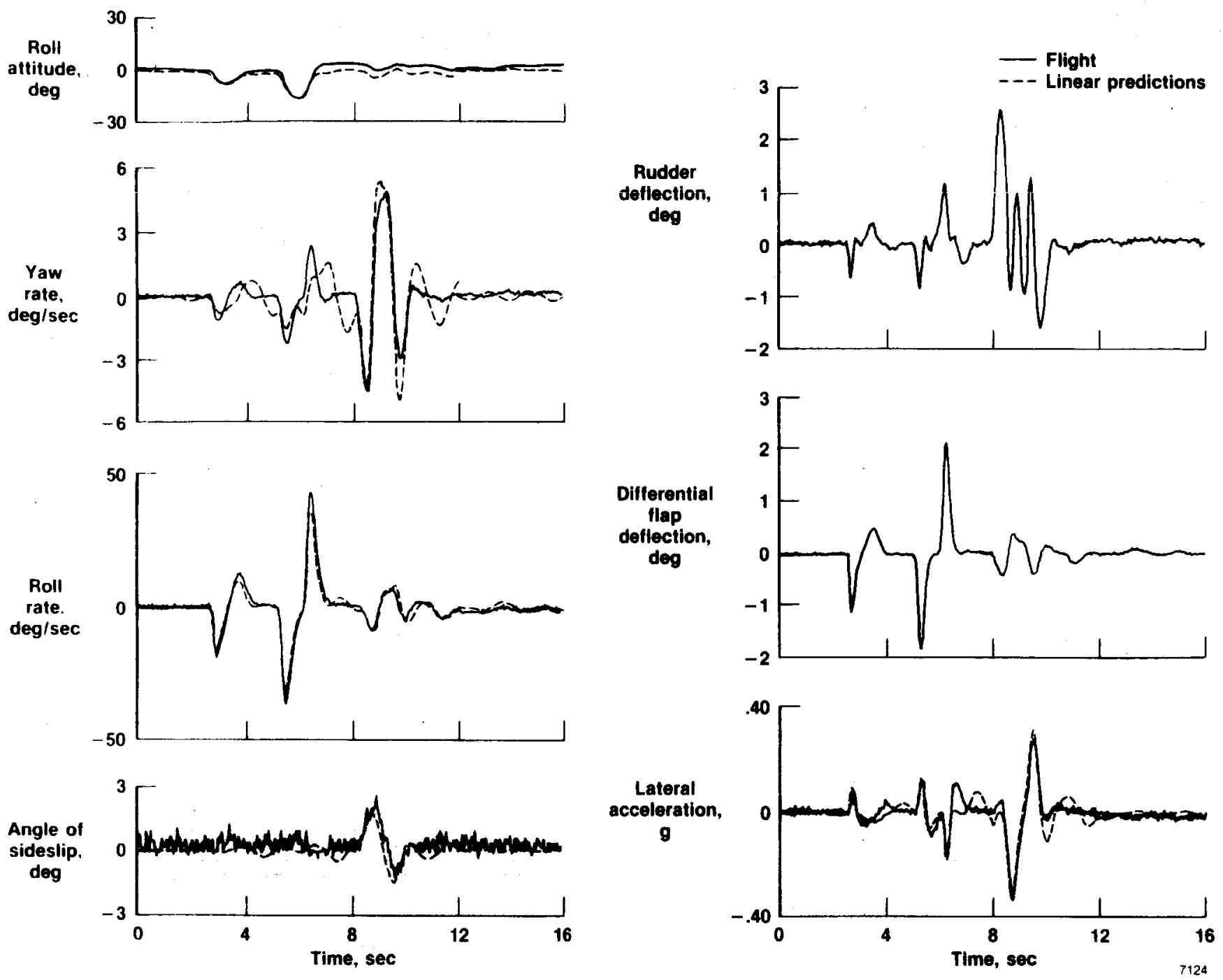

Fig. 11 Response of the X-29A to a differential flap and rudder input compared with linear simulation results. 

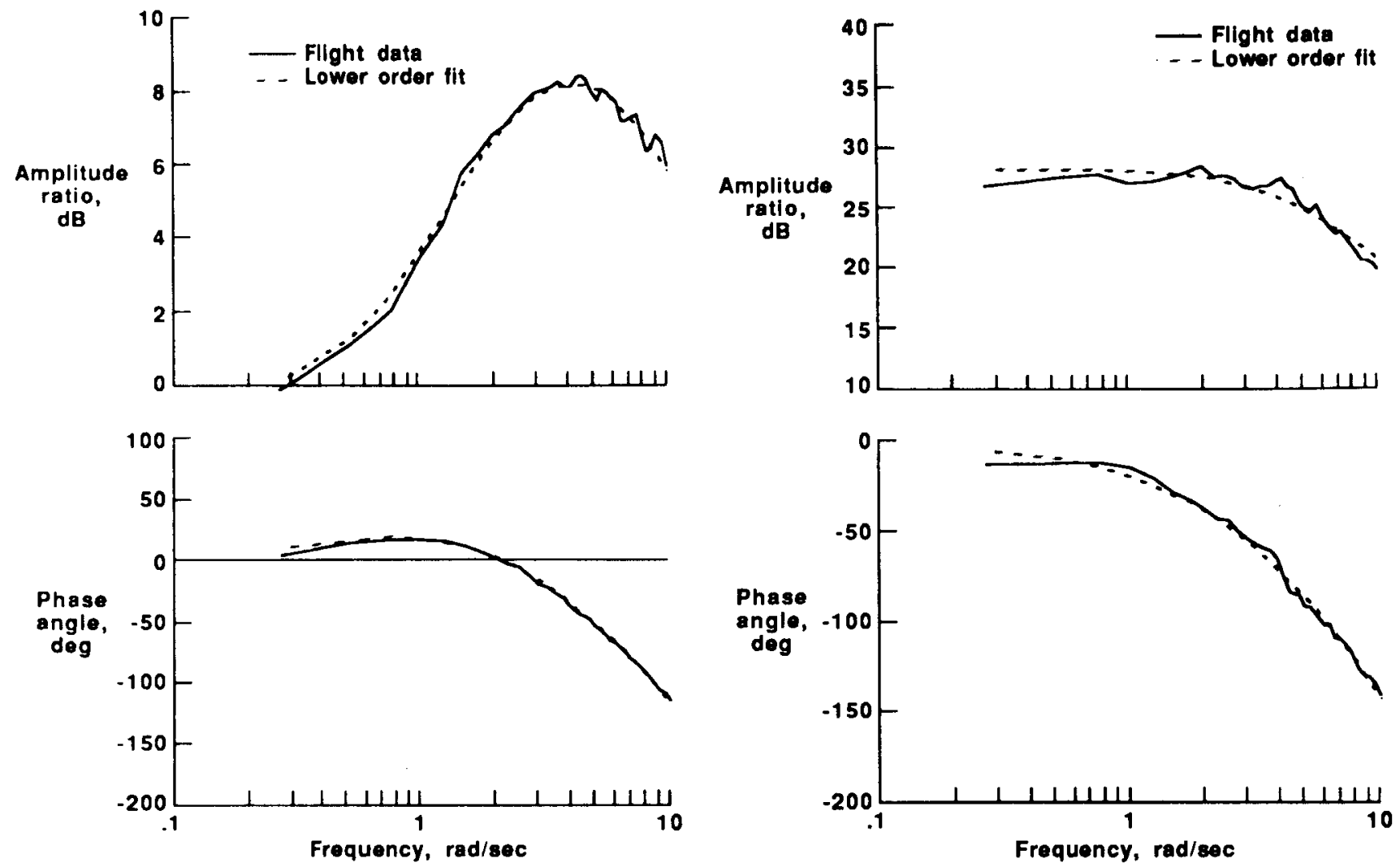

Fig. 12 Longitudinal lower order system match of the pitch rate due to longitudinal stick transfer function.

Fig. 13 Lateral lower order system match of the roll rate due to lateral stick transfer function.

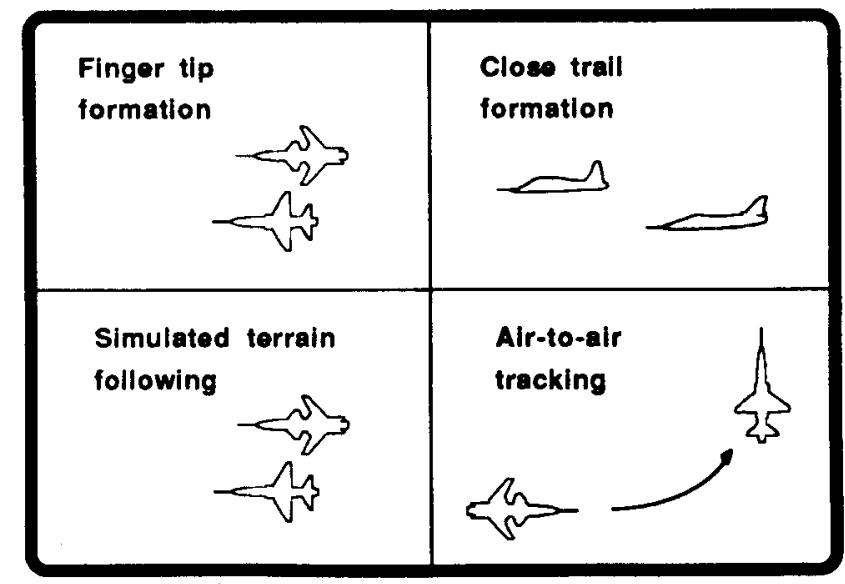

Fig. 14 Pilot evaluation tasks. 


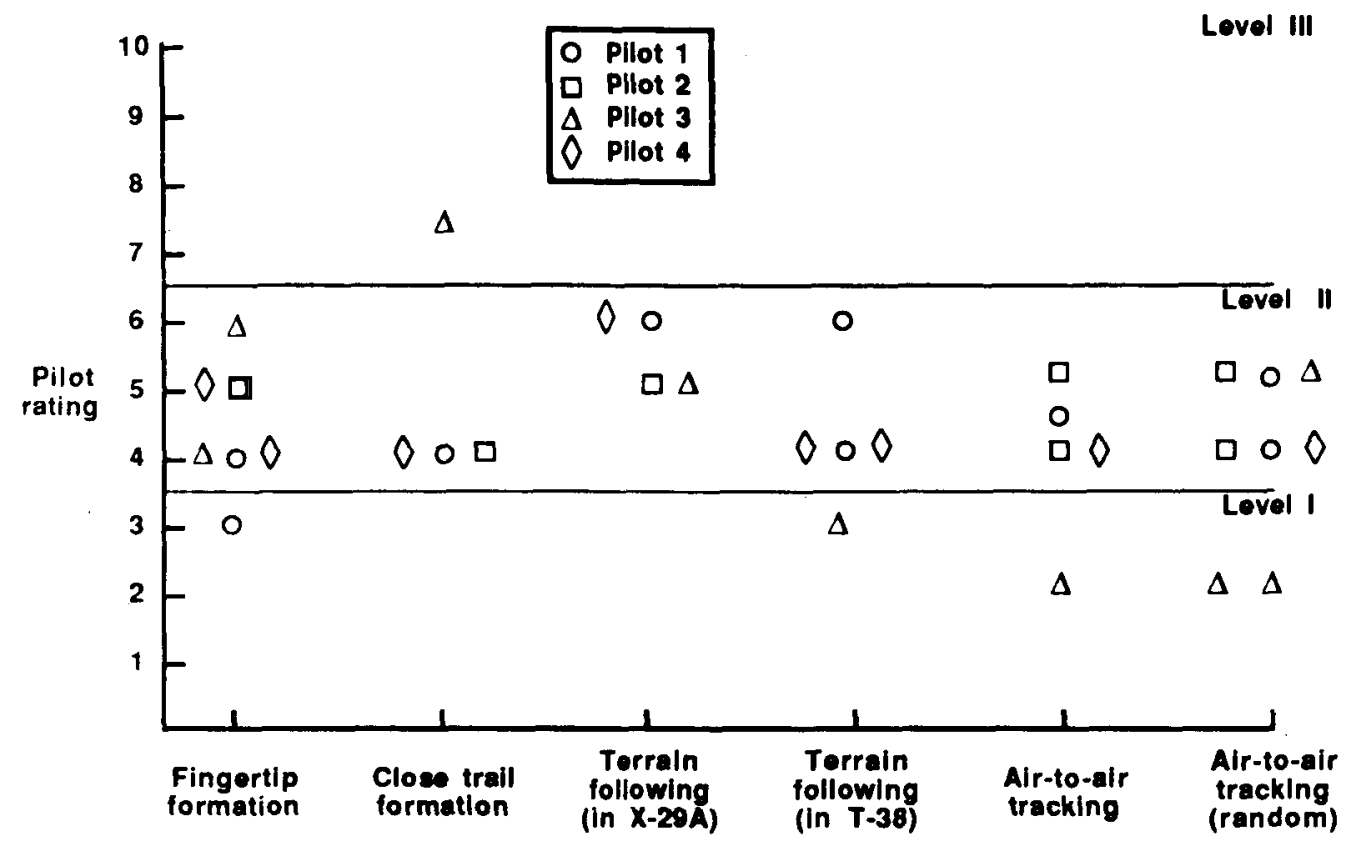

Fig. 15 Pilot rating summary. 


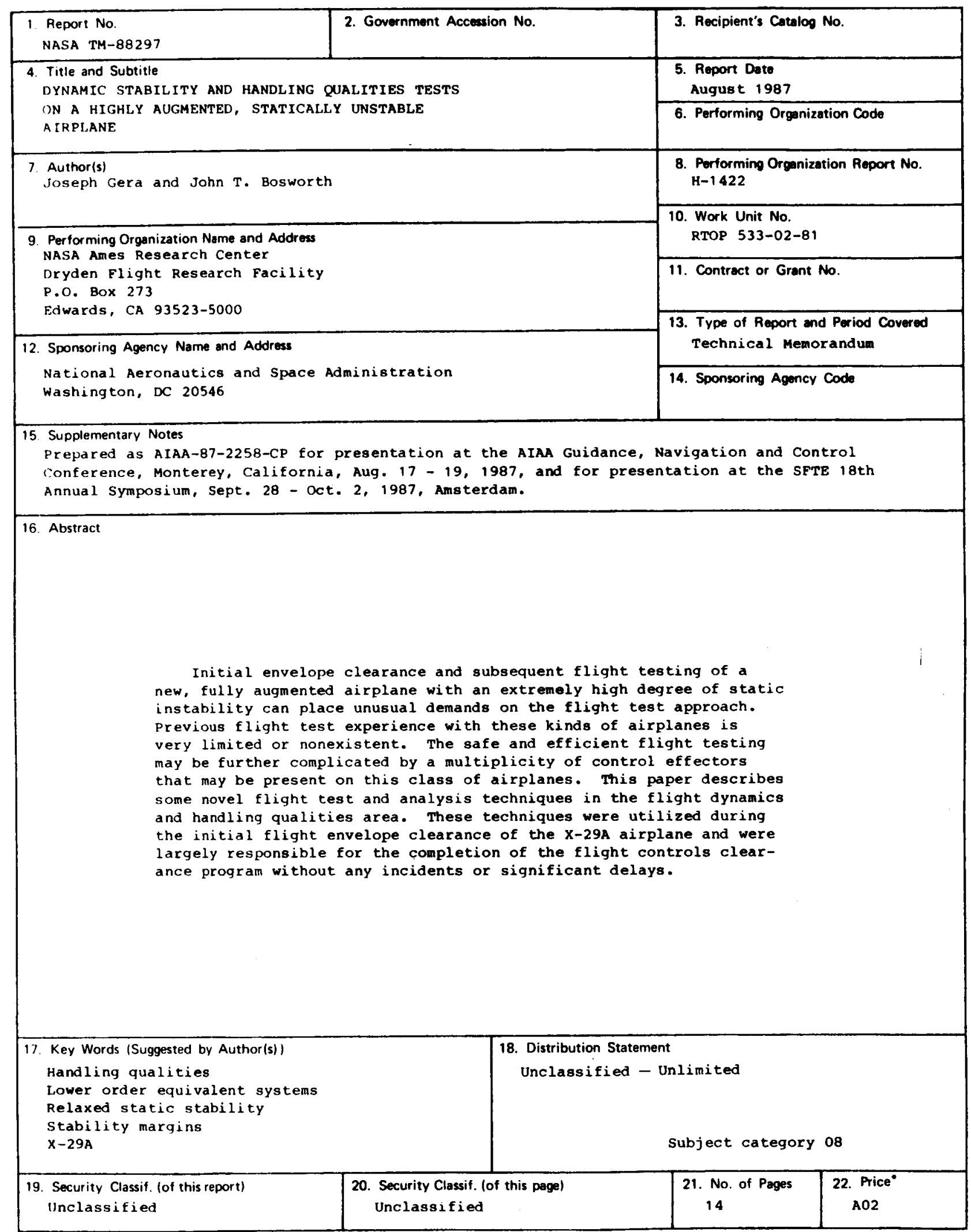

*For sale by the National Technical Information Service, Springfield, Virginia 22161. 